Available online at: https://proceeding.researchsynergypress.com/index.php/rsfconferenceseries1

RSF Conference Series: Business, Management and Social Sciences

e-ISSN 2807-5803/ p-ISSN 2807-6699

Volume 1 Number 1 (2021): 44-51

\title{
Counterfeit Products in Online Platform: A Systematic Review
}

\author{
Nor Sheena Andon \\ Universiti Teknologi MARA, Malaysia
}

\begin{abstract}
The counterfeit products had been widely consumed even before the online platform usage among the consumers emerges. There are several reasons the author seeks to find on how such phenomenon occurred hence, making the purpose of this paper to identify how consumers are nowadays consuming counterfeited products impulsively through the online platform and how does it happen using the explanation of the underlying theory. The present study's undergone a systematic review process which is the question formulation, locating studies, study selection/evaluation, analysis/synthesis and reporting/using results. The result of the study is discussed in line with the objective to answer the formulated research questions on the flow theory able to explain how online impulsive buying behaviour occurs among online users and how the online impulsive buying behaviour enhance the purchase of counterfeit products.
\end{abstract}

Keywords: counterfeit products; online impulsive buying behaviour; social media; flow theory

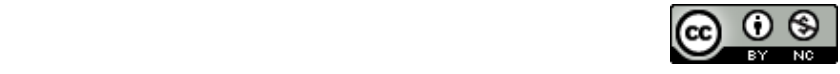

This is an open access article under the CC-BY-NC license

\section{INTRODUCTION}

The emergence of internet use in the 21st century has made the usage of it becoming a major role in our daily routine. If we make a bit of flashback, we can recall when we were in the primary school only a few computers available on the access centre to access the internet which some of it did not even have a stable internet connection. Contradictory to the world today, what a person needs to access the internet is anywhere inside the house whenever they need it. This new so-called major routine in the daily basis of life has caused people to develop compulsive internet use and has poor control over their usage time on the internet, particularly the social networking apps on their smartphones. Additionally, compulsive internet use (CIU) has also been associated with impulsive buying (Quinones et al., 2016), such as scrolling through their social networking sites or web browsing.

In China itself, the penetration of smartphones to the market reaches 88\% (Statista, 2021), while the usage of mobile phones has a total of up to $80 \%$ from the total digital time, which concludes that the use of smartphones is rapidly increasing among other digital platforms. On the other hand, with the excessive usage of smartphones, the demand for counterfeit products hiked tremendously when the users, especially among the millennials, encountered impulsive buying behaviour as a result of excessive usage of smartphones as it has become the major desire among the users especially millennials to possess material goods or service and it is a unique personality trait of materialistic people (Belk, 1988; Sirgy et al., 2021). Most people believed that a large number of material possessions is often reflected in how much they have gratitude in life and portrays the quality of life (Dittmar et al., 2014).

Therefore, these millennials who are prone to practice materialism choose to buy counterfeit products as the solution to fulfil that desire, as defined by Belk (1984), where materialism become "the 
importance a consumer attaches to worldly possessions. Counterfeit products are products that are produced without obtaining the authorization of using other legally registered products' trademarks (Chaudhry and Zimmerman, 2009). Findings by Dittmar et al. (2014) stated that advertising is a key determinant of materialism because an enormous number of individuals spent their time compulsively on the internet, which has played the role of influencing their purchase intention (Islam et al., 2021). As a result, the counterfeit product has increase significant concern among scholars, policymakers, companies and non-governmental organizations due to the rise of its sales and how it has an important influence on a country's economic growth (Bian et al., 2016; Eisend, 2019). It has been reported that counterfeit and pirated products have taken over approximately five to ten percent of the international market (Davidson et al., 2017).

The International Chamber of Commerce (ICC) (2009) found that the value of counterfeit products will increase to $\$ 1.7$ trillion by 2016 , which is converted to current global economic output it is equal to 2\%. According to Haque et al. (2009), China, Thailand, India, and Malaysia has been considered as the "home for piracy" as well as the "world's most violator of intellectual property rights and worst counterfeit offender". In Malaysia itself, Havoscope Global Market Index (2010) reported that the value for a counterfeit product in the country is amounting to RM 378 million in recent years, and the numbers have no sign of stopping.

Hence, the purpose of this paper is to identify how consumers are nowadays consuming counterfeited products impulsively through online platforms and how does it happen along the process using the explanation of the identified theory. It is consistent with the current study research questions that the author seeks to find, which are how the flow theory leads to online impulsive buying behaviour and how does online impulsive buying behaviour enhance the purchase of counterfeit products. The current review found that the context of social commerce or (S-commerce) and the impulsive buying behaviour are explained with the use of the "flow" theory (Lu et al., 2009). The result of this study confirms what is the significant factor causing consumers to buy counterfeit products and how does the flow theory explains online impulsive buying behaviour. The study presented in this paper is also supported by the relevant literature that shows varying key themes that have been identified by the researcher.

\section{LITERATURE REVIEW}

Counterfeit products

Nordin (2009); Staake et al. (2009) indicated that counterfeit goods the unauthorized products possessing low quality and standards that were not manufactured by their original producer. Mohamed (2012) found that apart from luxury products being counterfeited, the product categories have also turned to another such as the consumer goods like digital products such as music and software, spare parts for vehicles and aircraft, cosmetics, razor blades, washing powder and clothes, food and pharmaceuticals, DVDs, CDs, electronic devices, textiles, military items, wine, cigarettes, pesticides and fertilizers.

Research says that consumers are the collaborators of the counterfeiters when they purchase counterfeit products knowingly (Prendergast et al., 2002). The past few decades have shown a rapid increment of the market for counterfeit products (Phau and Teah, 2009). Plus, it had become more interesting when the technologies in manufacturing and commercialization at the global stage advanced progressively where at some point the consumers hardly differentiate between the genuine and fake products (Liu et al., 2015; Orvell, 1989). 
Online impulsive buying behaviour

Impulsive buying is defined as the urge to buy something spontaneously, unreflectively, immediately and kinetically, which is stimulated by a sudden, often powerful and persistent urge (Rook and Fisher, 1995). In this study, the behaviour is discussing in the context of online purchase through the online platform such as SNS, websites and apps. Wu et al. (2020) emphasized that online shopping contributes a higher chance of leading to impulsive buying than traditional shopping. The cause is none other than the virtual process of online transactions that give illusions to the users that they were not spending their own money when it occurred (Park et al., 2012).

This affirms that since buying online does not involve meeting face-to-face between the seller and buyer or the need to pay with physical cash, and online transactions have provided the users with the thought like they are not spending their money. This is because it seems only numbers and words were being displayed on the screen, and users tapped wherever they want to make the purchase without realizing the numbers in their account bank is the current balance, and it is decreasing. To some extent buying unnecessary goods they think they need which were not. Hu et al., (2019) found that online platform has influenced individual lives and consumption behaviour.

Flow theory

"Flow" theory is constructed as a feeling being carried away is experienced by users in an act without knowing they no longer care about anything (Huang, 2016). Researchers stated that "flow" has concerns with a state of being totally controlled, absorbed and enjoyment as online users engage themselves in a compulsive buying behaviour on social media networking sites (SNS) (Baron and Kenny, 1986; Ciarrochi et al., 2016; Liu et al., 2016). This theory described how online impulsive buying behaviour occurred at the beginning stage up until its known impacts which are why called 'flow' as it happens unconsciously by the users.

A study by Hoffman and Novak (1996) emphasized that the flow of experience undergone by the online users making their exploratory customer behaviour more convenient, making them spent greater time on certain SNSs or other online platforms to search for goods or services. It is a normal process occurring as a human where people tend to crave for more when they see more, plus conveniently it happens on one tap like a magic wand. Hence, it enhanced the chance of online impulsive buying behaviour, particularly on the latest goods and services or engaging in exploratory processes which ended up in buying (Huang, 2016).

\section{RESEARCH METHOD}

The researcher has carried out a review on the counterfeit products literature, identifying the themes and organized them into key themes that are only relevant to the study. As stated by Snyder (2019), these principles promote reproducibility and transparency in the review process. It is suggested there are five steps in producing a systematic review which are Question formulation, Locating studies, Study selection/evaluation, Analysis/synthesis and Reporting/using results (Denyer \& Tranfield, 2009). The research questions are:

RQ1) How flow theory leads to online impulsive buying behaviour?

RQ2) How does online impulsive buying behaviour enhance the purchase of counterfeits products? 
Question formulation

From the initial assessment of the literature, the research scope, research questions and inclusion/exclusion criteria have been established. On top of that, two research questions have been formulated which RQ1) How flow theory leads to online impulsive buying behaviour? RQ2) How does online impulsive buying behaviour enhance the purchase of counterfeits products? These research questions will be answered in the discussion part with the support of relevant literature and previous studies.

Locating studies

We had identified the relevant studies by focusing on the online database such as Emerald Insight, Scopus and Google Scholar, which includes specific fields that are relevant and related to the scope of the study. This is to ensure a deeper understanding of the study while referring to other conference proceedings. Academic literature has provided the study with valuable insights to enlighten the "what", "why", and "how" on the practice of counterfeit products purchases.

The keywords used were "counterfeiting", "counterfeit products", "counterfeit products in social media", "counterfeit products communication", and "counterfeit products in online platforms". Upon searching for the titles and keywords, abstracts were focused too. TheThe keywords were put to limits to avoid any peculiarities that potentially lead to misinformation and disinformation on the concepts.

Study selection and evaluation

We had excluded the articles that focus on the procedures or strategies to combat counterfeit products and articles are written in English only has been included. We have identified 110 articles consisting of 107 articles and three conference papers. The overall total number of publications included that are only relevant to the study is 43 articles, including the conference papers.

Analysis and synthesis

The author coded the identified articles according to the themes independently in order to provide a broader and clearer understanding while identifying the themes. The analysis of the articles made by the author has come to their final decision to place the themes as counterfeit products, flow theory and online impulsive buying behaviour.

\section{GENERAL CHARACTERISTICS}

Publication year

The articles' publication year chosen was from 2015 until the current year of 2021, which is more or less five years back of published studies. In this study, the most recent article regarding counterfeit products in the online platform was by Islam et al. (2021). The issue of counterfeit products had been an issue before the internet emerges globally, but the published studies regarding its effects are lesser than its determinants in recent years. Hence, we decided to formulate the question on how exactly it happens to individuals on impulsively buying counterfeit products.

\section{Disciplines}

We reviewed the articles from various disciplines, which are the majority of the marketing \& management, consumer behaviour and digital marketing, based on the interest of the study to help the author understand the phenomenon of counterfeit products among the consumers and what are the 
reasons they act in such a way. The reason why we are interested in the purchase of counterfeit products is that to enhance a deep understanding of how the online users involved in the act of counterfeit products purchased in recent years, specifically during the internet age where everything can be done online.

\section{FINDINGS AND DISCUSSION}

This review provides a systematic overview of the relevant literature on counterfeit products purchase, online impulsive buying behaviour and the flow theory. The themes are discussed altogether to confirm how the themes connected to one another and then identifying future directions from the marketing perspective according to the research question that has been formulated, which are:

RQ1) How flow theory leads to online impulsive buying behaviour?

Studies show that social media and online messaging systems had the purchasing and selling transactions shifted into the platforms (Bitar, 2013; Crompton, 2015). It indicates that the consumption of counterfeit products is easier because the accessibility of counterfeit products for both counterfeiters and its consumers simply at their taps through mobile phones where the former can sell and promote easily while the latter can buy it online and then wait for it to be delivered to their doorsteps. Ting and Tsang (2014); Davidson et al. (2019) confirmed that the internet is an ideal avenue for selling counterfeit products, causing problems for manufacturers and marketers of genuine luxury products. What's even more concerning for the producer of genuine products is, Wang et al. (2019) confirm that the promotional efforts only to find the effort only leads to greater consumption of counterfeit products.

The phenomenon of triggered online impulsive buying behaviour is explained with the "flow theory" as it is associated with the usage of the internet, especially in S-commerce or social commerce. As the flow theory defines that it is an optimum experience where users are so carried away in an exercise until they no longer care about anything which applies to the users' temporary condition of total control, absorption and enjoyments as they engage on the SNSs to make online purchases (Barron et al., 1986; Calvo-Porral et al., 2017; Ciarrochi et al., 2016; Liu et al., 2016). It implies that the users are very enjoying passionately and intensely in the activities that are deemed entertaining for them. Even so, the flow of experience is crucial for online users to ensure continuous S-commerce because of the equal chance for large discounts, additional gifts on extra purchases and important news for online users (Islam et al., 2018).

Research has confirmed that flow is playing an important role to understand the online behaviour of users in the s-commerce in making the exploratory consumer behaviour ease which also caused the online consumers to spend more time on SNSs, websites or other online media to find products and services (Hoffman and Novak, 1996). This means that when online consumers spend more time on SNSs or online platforms, it enhances the possibility of impulsive online buying, especially when it comes to new products or services, as well as increasing the practice of exploratory processes (Huang, 2016).

RQ2) How does online impulsive buying behaviour enhance the purchase of counterfeits products?

After we discovered that the flow theory is practical in explaining the online impulsive buying behaviour encountered by the consumers through the flow of experience where they got carried away, the reason such behaviour occurred is because of the irresistible experience that influences users' behaviour (Zafar et al., 2021). As a result, online platforms have to change individual lives and their consumption behaviour (Hu et al., 2019); thus, when consumption behaviour changed due to the impulsive buying 
behaviour via online, Ozimek and Forster (2014) confirm that users spent more time in Facebook is has higher materialistic tendencies.

Singh and Sahni (2019) signify that the high tendency of materialism shows a positive relationship with the consumption of counterfeit products. Hence, when we talk about materialism, it involves the obsession of consuming more products is high. Additionally, those who are materialistic are more concerned about guarding their social status and money-oriented Dittmar et al., (2014), which is why these people tend to buy counterfeit products even though they know it is genuine or not as long as they can keep their guard high.

Another reason that triggered the online impulsive buying behaviour is the people who seek novelty-seeking values for their consumption of products or services (Islam et al., 2021). People with a materialistic tendency are more excited to receive brands that can be perceived as "carefully crafted, unique and conspicuous" (Davidson et al., 2017). Product conspicuousness is described as the brand's tendency to be apparent, noticeable and traceable to other (Grimm et al., 1999). Therefore, it can be concluded that the consumers would go more for counterfeits products as it has higher visibility to others and generate a willingness to buy (Wan et al., 2009).

Hence, suggestions for future research in the marketing perspective should focus on how firms take advantage of this theory, especially the producer of genuine products, to combat the counterfeiters imitating their products, such as in terms of more user-generated content and maybe reconsidering the price by providing switching cost. This is proven when Hidayat and Diwasasri (2013), in their research, says it is common for counterfeiters to know that consumers do not care about the quality, but they want to buy branded-looking products at a lower price. This is because individuals worldwide are more anxious about their social position, status and social class (Dittmar et al., 2014; Griffin et al., 2004).

\section{CONCLUSION AND FURTHER RESEARCH}

The present study represents the phenomenon of how the purchase of counterfeit products is related to consumer behaviour, which is the online impulsive buying behaviour and how to flow theory explains more clearly. We carried out the review based on the analysis and synthesis from the past studies that evidently confirms the phenomenon using the secondary data, which is articles. The study highlights the flow theory and online impulsive buying behaviour thus, providing a clearer and broader understanding on what are the reasons that consumers tend to be impulsive when buying online and how does it make consumers wanted to buy counterfeits products instead of genuine ones.

The definition of the themes is also discussed in the paper to clarifies the interrelationships of the themes. Even though the sources may be limited on the strategies and procedures to combat the counterfeit products, we were able to present the phenomenon, but the effects it is not thoroughly discussed. This is due to the published studies are mostly pointing out the determinants and factors of the purchase of counterfeit products. Overall, we have applied the meaningful keywords in the study and reliable database to provide relevant articles so that the research questions can be answered clearly.

The contribution of this paper could provide a clearer understanding for the companies on their marketing activities which is stated in the findings intensive marketing on their products has huge impacts on the counterfeited products because more consumers are exposed to the promotional activities yet making them want to consume the product without considering it is genuine or not. Hence, it is crucial for the marketers of a company to acknowledge that their successful marketing campaign not only led to achieving their marketing objectives but also 'opening ways' for the counterfeiters to imitate their products and sell them to their potential market that may be demanded a lower price. 
On the other hand, the limitation of this study exists when the source of the author's findings is mainly on the secondary data, mainly focusing on the literature on counterfeiting products. The discussion of counterfeit products phenomenon on the online platform is also limited nowadays considering the phenomenon is previously already existed even before the online platform emerges thus, leading to the limited source of how online platform has transformed the consumption of consumers towards the counterfeit products.

\section{REFERENCES}

Ouyang, Y., Huang, L., \& Wei, Z. Bin. (2021). Research on the Influence Mechanism of Precision Marketing on Online Consumer Behaviour based on the "S-O-R" Paradigm and Eroglu's (2001) Online Shopping Response Model: Take the TikTok platform as an example. In Proceedings - 2nd International Conference on E-Commerce and Internet Technology, ECIT 2021 (pp. 218-223). Institute of Electrical and Electronics Engineers Inc. https://doi.org/10.1109/ECIT52743.2021.00055

Hu, X., Chen, Z., Davison, R. M., \& Liu, Y. (2021). Charting consumers' continued social commerce intention. Internet Research, (72072013). https://doi.org/10.1108/INTR-07-2020-0397

Ming, J., Jianqiu, Z., Bilal, M., Akram, U., \& Fan, M. (2021). How social presence influences impulse buying behavior in live streaming commerce? The role of S-O-R theory. International Journal of Web Information Systems, ahead-of-print(ahead-of-print). https://doi.org/10.1108/ijwis-02-2021-0012

Islam, T., Pitafi, A. H., Akhtar, N., \& Xiaobei, L. (2021). Determinants of purchase luxury counterfeit products in social commerce: The mediating role of compulsive internet use. Journal of Retailing and Consumer Services, 62 (August 2020), 102596. https://doi.org/10.1016/j.jretconser.2021.102596

Domenico, G. Di, Sit, J., Ishizaka, A., \& Nunan, D. (2021). Fake news, social media and marketing: A systematic review. Journal of Business Research, 124(November 2020), 329-341. https://doi.org/10.1016/j.jbusres.2020.11.037

Tseng, W.-Y., Chiu, W., \& Leng, H. K. (2020). A comparative study of consumers' intention to purchase counterfeit outdoor products in Taiwan and Hong Kong. Journal of Asian Business and Economic Studies, ahead-of-print(ahead-of-print). https://doi.org/10.1108/jabes-02-2020-0011

Hirakawa, M., \& Iijima, J. (2011). A study on integrated mobile service using digital watermark for various information carriers. Proceedings - 2011 10th International Conference on Mobile Business, ICMB 2011, 283-291. https://doi.org/10.1109/ICMB.2011.13

Phau, I., Sequeira, M., \& Dix, S. (2009). Consumers' willingness to knowingly purchase counterfeit products. Direct Marketing, 3(4), 262-281. https://doi.org/10.1108/17505930911000865

Fahad, M. (2020). Impact of Perception of Counterfeits on Customers ' Purchase Intention of Genuine Luxury Brands : The Mediating Effect of Brand Image and Brand Awareness, II(Vii), 131-138.

Evans, B. P., Starr, R. G., \& Brodie, R. J. (2019). Counterfeiting: conceptual issues and implications for branding. Journal of Product and Brand Management, 28(6), 707-719. https://doi.org/10.1108/JPBM12-2017-1706

Bian, X., \& Moutinho, L. (2011). Counterfeits and branded products: Effects of counterfeit ownership. Journal of Product and Brand Management, 20(5), 379-393. https://doi.org/10.1108/10610421111157900

Anggraeni, A., \& Rachmanita. (2015). Effects of Brand Love, Personality and Image on Word of Mouth; the Case of Local Fashion Brands Among Young Consumers. Procedia - Social and Behavioral Sciences, 211(September), 442-447. https://doi.org/10.1016/j.sbspro.2015.11.058 
Bian, X., \& Moutinho, L. (2011). The role of brand image, product involvement, and knowledge in explaining consumer purchase behaviour of counterfeits: Direct and indirect effects. European Journal of Marketing, 45(1), 191-216. https://doi.org/10.1108/03090561111095658

Stumpf, S. A., Chaudhry, P. E., \& Perretta, L. (2011). Fake: can business stanch the flow of counterfeit products? Journal of Business Strategy, 32(2), 4-12. https://doi.org/10.1108/02756661111109725

Mitchell, N. A., Scheinbaum, A. C., Li, D., \& Wang, W. (2017). Purse parties: A phenomenology of inhome counterfeit Luxury events. Review of Marketing Research, 14, 227-255. https://doi.org/10.1108/S1548-643520170000014014

Assi, S., Thomas, J., Haffar, M., \& Osselton, D. (2016). Exploring consumer and patient knowledge, behavior, and attitude toward medicinal and lifestyle products purchased from the internet: A web-based survey. JMIR Public Health and Surveillance, 2(2). https://doi.org/10.2196/publichealth.5390

Tang, F., Tian, V. I., \& Zaichkowsky, J. (2014). Understanding counterfeit consumption. Asia Pacific Journal of Marketing and Logistics, 26(1), 4-20. https://doi.org/10.1108/APJML-11-2012-0121

Kassim, N. M., Zain, M., Bogari, N., \& Sharif, K. (2021). Why do consumers buy counterfeit luxury products? A tale of two major cities in two different countries. Asia Pacific Journal of Marketing and Logistics (Vol. 33). https://doi.org/10.1108/APJML-06-2019-0361 